\title{
Factors Predicting the Need for Early Surgical Intervention for Small Bowel Obstruction
}

\author{
Young Jae Cho, In Seok Park, Jungbin Kim, Hyun Jin Cho, Geum Hee Gwak, Keun Ho Yang, \\ Byung Noe Bae, Ki Hwan Kim \\ Department of Surgery, Inje University Sanggye Paik Hospital, Seoul, Korea
}

Purpose: Small bowel obstruction (SBO) is a common disease that requires hospitalization. The most common cause of $\mathrm{SBO}$ is postoperative adhesion. Delayed timing of operations in patients who need surgical intervention results in mortality or morbidity. A number of studies on SBO have established criteria for emergency surgery. However, few objective clinical parameters are available for screening patients who need a delayed operation. Therefore, we analyzed factors that affect the clinical course of SBO to select appropriate therapeutic plans for reducing the risk of complications in these patients.

Methods: We investigated the clinical characteristics of patients admitted to the surgery department of our hospital between January 1, 2015, and December 31, 2016, who were diagnosed with SBO. Patients were divided into an operative treatment group $(n=12)$ and a conservative treatment group $(n=96)$. We compared clinical characteristics between the 2 groups.

Results: The operative treatment group underwent more operations before $\mathrm{SBO}$ than the conservative treatment group $(\mathrm{P}=0.007)$. Initial leukocyte counts $(\mathrm{P}=0.004)$ and $\mathrm{C}$-reactive protein $(\mathrm{CRP})$ levels $(\mathrm{P}=0.028)$ were elevated in the operative group. Body mass index (BMI) was lower in the operative group $(\mathrm{P}=0.013)$.

Conclusion: The number of operations before SBO, leukocyte counts, CRP levels, and BMI were useful parameters for selecting patients who needed an urgent operation for SBO.

Keywords: Body mass index; C-reactive protein; Leukocyte; Small bowel obstruction

\section{INTRODUCTION}

Small bowel obstruction (SBO) is defined as a status that is a surgical emergency resulting from the inhibited passage of bowel contents [1]. SBO is a major cause of hospital admission [2]. The most common cause of SBO is adhesion, accounting for approximately $75 \%$ of all cases, followed by malignancy and inflammatory bowel disease [3]. Studies have aimed to prevent postopera-

Received: Jul 27, 2019 • Revised: Aug 29, 2019 - Accepted: Sep 30, 2019 Correspondence to: In Seok Park, M.D.

Department of Surgery, Inje University Sanggye Paik Hospital,

1342 Dongil-ro, Nowon-gu, Seoul 01757, Korea

Tel: +82-2-950-1017, Fax: +82-2-933-9389, E-mail: S5507@paik.ac.kr ORCID: https://orcid.org/0000-0002-6415-9307

(C) 2020 The Korean Society of Coloproctology

This is an open-access article distributed under the terms of the Creative Commons Attribution NonCommercial License (https://creativecommons.org/licenses/by-nc/4.0) which permits unrestricted noncommercial use, distribution, and reproduction in any medium, provided the original work is properly cited. tive adhesion, but no appropriate method has been established [4]. Therefore, the appropriate treatment for SBO remains an important surgical issue. Most cases of SBO are successfully treated with conservative management. However, some demand opportune surgical interventions [5]. Failing to perform appropriate surgical interventions increases mortality and morbidity.

According to a study from 2013, the incidence rate of complications such as surgical site infection, pneumonia, and sepsis and mortality is significantly higher in groups of patients whose surgical treatment is delayed by $>24$ hours compared to those who received early operative intervention for adhesive SBO [6].

Studies on SBO found some indications for emergency surgery. However, the analysis of specific clinical factors for delayed operation is lacking $[7,8]$. Selecting operative management is difficult for patients who previously recovered through conservative care or who are at the boundary of indications for operative management. The aim of this study was to improve the therapeutic prognosis of SBO by identifying predictive factors for the early selec- 
tion of patients who need operative management.

\section{METHODS}

This was a single-center retrospective study conducted in the Surgery Department of our hospital from January 1, 2015, to December 31, 2016. The study protocol was reviewed and approved by the Institutional Review Board (IRB) of our hospital (approval number: SGPAIK 2018-03-024). The IRB waived the need for informed consent for this retrospective chart review.

\section{Study population}

Patients admitted to the Surgery Department of our hospital with a diagnosis of SBO between January 1, 2015, and December 31, 2016, were evaluated. Patients who were readmitted after discharge during the study period; who had ileus within 1 month after surgery; who underwent surgery within 3 days after admission because they met immediate surgery criteria such as ischemic change or closed loop in computed tomography (CT); and patients with colon or rectal lesions were excluded.

Included patients were divided into 2 groups by conservative treatment or operative treatment. The conservative treatment group included patients whose symptoms improved with fasting, intravenous antibiotics, and total parenteral nutrition. The operative treatment group was patients whose clinical features improved after surgical interventions such as bowel resection or band adhesiolysis and those who died in spite of surgical interventions.

We reviewed baseline clinicopathologic characteristics such as age, sex, body weight, height, body mass index (BMI), history of smoking or alcohol consumption, diabetes mellitus, hypertension, and number of operations before index surgery. We also studied factors associated with the index surgery. Index surgery was defined as the last operation before SBO onset [9]. Factors included time to hospitalization for SBO after index surgery and characteristics of the index surgery such as malignancy, laparotomy, bowel resection, emergency, intraperitoneal drainage tube use, operation time (from incision to suture), American Society of Anesthesiologists (ASA) physical status classification, and hospitalization duration. Initial vital signs and laboratory findings such as systolic blood pressure, diastolic blood pressure, body temperature, heart rate, respiratory rate, hemoglobin level, leukocyte and differential counts, and C-reactive protein (CRP) level were reviewed. We compared the results between groups using statistical analyses. We also reviewed the outcomes of the operative management group.

\section{Statistical analyses}

Continuous variables were analyzed using the Mann-Whitney Utest. The Kruskal-Wallis test was used for categorical variables. Multiple logistic regression analysis was performed for related factors with P-values $<0.05$ in univariate analysis. All analyses were considered statistically significant at $\mathrm{P}$-value $<0.05$. Statistical analysis was performed using IBM SPSS Statistics ver. 24.0 (IBM Co., Armonk, NY, USA).

\section{RESULTS}

We investigated the clinical features of patients who were diagnosed as having SBO between January 1, 2015, and December 31, 2016. During the study period, 172 patients were hospitalized for SBO. Patients with ileus within 1 month after surgery $(n=19)$; who underwent surgery within 3 days after admission because they met immediate surgery criteria such as ischemic change and closed loop on CT $(n=18)$; and patients with colon or rectal lesions $(n=27)$ were excluded. The 108 included patients were divided into a conservative care group $(\mathrm{n}=96)$ and an operative management group $(n=12)$ (Fig. 1).

Baseline clinical data analysis showed no significant differences between groups on age, sex, height, history of smoking or alcohol consumption, diabetes mellitus, or hypertension. BMI $(\mathrm{P}=0.013)$ (Table 1) was significantly higher in the conservative care group than the operative management group. The number of operations before index surgery was significantly higher in the operative management group than the conservative care group $(\mathrm{P}=0.007)$ (Table 1).

No significant differences were found between the 2 groups in time to hospitalization for SBO after index surgery or characteristics of the index surgery such as malignancy, laparotomy, bowel resection, emergency, or intraperitoneal drainage tube (Table 2).

Initial vital signs and laboratory findings demonstrated no significant differences in systolic blood pressure, diastolic blood pressure, body temperature, heart rate, respiratory rate, hemoglobin level, or differential leukocyte count between the 2 groups. Initial leukocyte count $(\mathrm{P}=0.004)$ (Table 3$)$ and $\mathrm{CRP}$ level $(\mathrm{P}=$

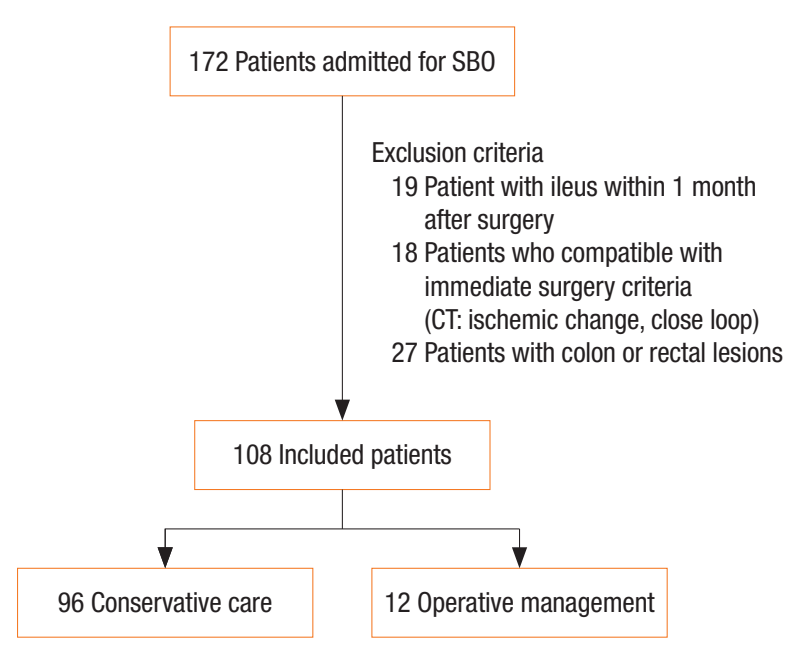

Fig. 1. Study population of this study. SBO, small bowel obstruction; CT, computed tomography. 
0.028) (Table 3) were significantly higher in the operative management group than the conservative care group.

\section{Multiple logistic regression analysis}

To analyze independent factors, multiple logistic regression analysis was performed for variables with P-values $<0.05$ for each group (Tables 1-3). Among the factors, the number of operations before SBO was significantly higher in the operative management group than the conservative care group and was identified as independent (odds ratio, 7.50; 95\% confidence interval, 1.75-32.21;

Table 1. Baseline demographic data of each group

\begin{tabular}{|c|c|c|c|}
\hline Characteristic & $\begin{array}{c}\text { Conservative } \\
\text { care } \\
(n=96)\end{array}$ & $\begin{array}{c}\text { Operative } \\
\text { management } \\
(\mathrm{n}=12)\end{array}$ & P-value \\
\hline Sex & & & 0.309 \\
\hline Male & $47(49.0)$ & $4(33.3)$ & \\
\hline Female & $49(51.0)$ & $8(66.7)$ & \\
\hline Age (yr) & & & 0.973 \\
\hline$<60$ & 38 (39.6) & $6(50.0)$ & \\
\hline$\geq 60$ & $58(60.4)$ & $6(50.0)$ & \\
\hline $\mathrm{BMI}\left(\mathrm{kg} / \mathrm{m}^{2}\right)$ & & & $0.013^{*}$ \\
\hline$<18.5$ & $9(9.4)$ & $0(0)$ & \\
\hline $18.5-22.9$ & $43(44.8)$ & 10 (83.3) & \\
\hline $23.0-24.9$ & $24(25.0)$ & $2(16.7)$ & \\
\hline$\geq 25.0$ & $20(20.8)$ & $0(0)$ & \\
\hline History of smoking & & & 0.687 \\
\hline Yes & $12(12.5)$ & $2(16.7)$ & \\
\hline No & $84(87.5)$ & $10(83.3)$ & \\
\hline History of alcohol consumption & & & 0.879 \\
\hline Yes & $26(27.1)$ & $3(25.0)$ & \\
\hline No & 70 (72.9) & $9(75.0)$ & \\
\hline Diabetes mellitus & & & 0.849 \\
\hline Yes & 14 (14.6) & $2(16.7)$ & \\
\hline No & $82(85.4)$ & $10(83.3)$ & \\
\hline Hypertension & & & 0.435 \\
\hline Yes & $35(36.5)$ & $3(25.0)$ & \\
\hline No & $61(63.5)$ & $9(75.0)$ & \\
\hline No. of operations before SBO & & & $0.007^{\star}$ \\
\hline 1 & $59(61.5)$ & $6(50.0)$ & \\
\hline 2 & 31 (32.3) & $2(16.7)$ & \\
\hline 3 & $5(5.2)$ & $2(16.7)$ & \\
\hline 4 & $1(1.0)$ & $2(16.7)$ & \\
\hline
\end{tabular}

Values are presented as number (\%).

BMI, body mass index; SBO, small bowel obstruction.

${ }^{*} \mathrm{P}<0.05$, statistical significance.
Table 2. Factors associated with index surgery

\begin{tabular}{|c|c|c|c|}
\hline $\begin{array}{l}\text { Factors associated with index } \\
\text { surgery }\end{array}$ & $\begin{array}{c}\text { Conservative } \\
\text { care } \\
(n=96)\end{array}$ & $\begin{array}{c}\text { Operative } \\
\text { management } \\
(n=12)\end{array}$ & P-value \\
\hline $\begin{array}{l}\text { Time to hospitalization for SBO after the } \\
\text { index surgery (yr) }\end{array}$ & & & 0.887 \\
\hline$<5$ & $22(22.9)$ & $4(33.3)$ & \\
\hline $5-10$ & $21(21.9)$ & $1(8.3)$ & \\
\hline$>10$ & $53(55.2)$ & $7(58.3)$ & \\
\hline Index surgery for malignancy & & & 0.476 \\
\hline Yes & $34(35.4)$ & $3(25.0)$ & \\
\hline No & $62(64.6)$ & $9(75.0)$ & \\
\hline Index surgery performed for laparotomy & & & 0.917 \\
\hline Yes & 79 (82.3) & $2(16.7)$ & \\
\hline No & $17(17.7)$ & $10(83.3)$ & \\
\hline Index surgery including bowel resection & & & 0.193 \\
\hline Yes & $53(55.2)$ & $3(25.0)$ & \\
\hline No & $43(44.8)$ & $9(75.0)$ & \\
\hline Emergent index surgery & & & 0.119 \\
\hline Yes & $36(37.5)$ & $2(16.7)$ & \\
\hline No & $60(62.5)$ & $10(83.3)$ & \\
\hline $\begin{array}{l}\text { Index surgery requiring intraperitoneal } \\
\text { drainage tube use }\end{array}$ & & & 0.068 \\
\hline Yes & $20(20.8)$ & $4(33.3)$ & \\
\hline No & 76 (79.2) & $8(66.7)$ & \\
\hline
\end{tabular}

Values are presented as number (\%). $\mathrm{SBO}$, small bowel obstruction.

Table 3. Initial vital signs and laboratory findings

\begin{tabular}{lccc}
\hline $\begin{array}{c}\text { Initial vital signs and } \\
\text { laboratory finding }\end{array}$ & $\begin{array}{c}\text { Conservative care } \\
(\mathrm{n}=96)\end{array}$ & $\begin{array}{c}\text { Operative management } \\
(\mathrm{n}=12)\end{array}$ & P-value \\
\hline $\begin{array}{l}\text { Initial systolic BP }(\mathrm{mmHg}) \\
120(90-160)\end{array}$ & $120(90-136)$ & 0.948 \\
$\begin{array}{c}\text { Initial diastolic BP(mmHg) } \\
70(50-100)\end{array}$ & $75(60-100)$ & 0.421 \\
$\begin{array}{c}\text { Initial body temperature } \\
\left({ }^{\circ} \mathrm{C}\right)\end{array}$ & $36.8(36.0-38.0)$ & $36.9(36.1-38.2)$ & 0.829 \\
$\begin{array}{l}\text { Initial heart rate (/min) } \\
\text { Initial respiratory rate }\end{array}$ & $80(37-118)$ & $83(62-108)$ & 0.141 \\
$\quad(/$ min) & $18(15-84)$ & $19(16-20)$ & 0.436 \\
$\begin{array}{l}\text { Initial hemoglobin level } \\
(\mathrm{g} / \mathrm{dL})\end{array}$ & $13.7(6.4-20.0)$ & $13.5(10.7-17.0)$ & 0.656 \\
$\begin{array}{l}\text { Initial leukocyte count } \\
(/ \mu \mathrm{L})\end{array}$ & $9,715(3,490-18,050)$ & $13,610(4,580-28,070)$ & $0.004^{*}$ \\
$\begin{array}{l}\text { Initial neutrophil count }(\%) \\
\text { Initial CRP level (mg/dL) }\end{array}$ & $0.3(40.6-92.9)$ & $71.9(59.9-94.3)$ & 0.434 \\
\hline
\end{tabular}

Values are presented as median (range).

$\mathrm{BP}$, blood pressure; CRP, C-reactive protein.

${ }^{*} \mathrm{P}<0.05$, statistical significance. 
$\mathrm{P}=0.007)$. However, BMI, initial leukocyte count, and initial CRP levels showed no significant differences between groups (Table 4).

\section{Operative management group outcomes}

In the operative management group, 12 patients underwent segmental resection of the small bowel. Four patients underwent adhesiolysis and one underwent bandlysis. The characteristics of outcomes for the operative management group are in Table 5.

\section{DISCUSSION}

The choice of surgical or conservative treatment for patients with SBO is still controversial [10]. Partial obstruction with no sign of strangulation usually necessitates conservative treatment for SBP. When complete obstruction or strangulation is confirmed, the treatment of choice is early surgery $[11,12]$.

This study was a retrospective analysis of clinical factors predicted to be associated with the therapeutic prognosis of SBO. We found several factors that could help identify patients who require early operative treatment.

A previous report suggested that patient age and ASA score are closely related to postoperative mortality in patients with SBO [13]. However, this factor was not statistically relevant in this

Table 4. Multiple logistic regression analysis for the operative management

\begin{tabular}{llc}
\hline Variable & \multicolumn{1}{c}{ OR $(95 \% \mathrm{Cl})$} & P-value \\
\hline $\mathrm{BMI}\left(\mathrm{kg} / \mathrm{m}^{2}\right)$ & $0.13(0.02-1.09)$ & 0.060 \\
No. of operations before SBO & $7.50(1.75-32.21)$ & $0.007^{*}$ \\
Initial leukocyte count $(/ \mu \mathrm{L})$ & $4.28(0.84-21.68)$ & 0.079 \\
Initial C-reactive protein level $(\mathrm{mg} / \mathrm{dL})$ & $3.67(0.72-18.74)$ & 0.118 \\
\hline
\end{tabular}

$\mathrm{OR}$, odds ratio; $\mathrm{Cl}$, confidence interval; $\mathrm{BMI}$, body mass index; SBO, small bowel obstruction.

${ }^{*} \mathrm{P}<0.05$, statistical significance. study. In agreement with a 2014 study by Meier et al. [9], we found that the number and type of previous abdominal operations did not affect the therapeutic prognosis of SBO. However, Lee et al. [14] found that history of operation was associated with the occurrence of early postoperative $\mathrm{SBO}(\mathrm{P}=0.044)$. In that study, patients who underwent surgery more than 3 times were more likely to have surgery for SBO. However, no difference was observed according to surgical method. This finding was because patients who received the operation once had the operation to treat their disease and patients who received the operation more than 3 times had the operation for SBO. The most common cause of $\mathrm{SBO}$ is reported to be adhesion due to a previous surgery, and risk of adhesion is expected to rise as the number of operations increases [3].

In 2012, Angenete et al. [15] reported an increased incidence for SBO after open surgery compared to laparoscopic surgery. Similar to a previous study, we found that the percentage of SBO was significantly higher for open surgery than for laparoscopic surgery. Generally, colorectal surgery is the most frequent type of surgery associated with SBO, followed by gynecological surgery, herniorrhaphy, and appendectomy $[16,17]$. This result seems to be related to the degree of small intestine manipulation.

BMI was significantly higher in the conservative treatment group than in the operative management group. A 2007 study by Davies on obesity and appendicitis in children compared a normal weight group with a very obese group, defined as $>2$ standard deviations over the mean weight for age. The appendicitis perforation rate was $20.0 \%$ in the very obese group and $25.5 \%$ in the normal weight group [18]. This paradoxical positive effect of obesity can be explained by higher expression of anti-inflammatory cytokines and antibacterial peptides in human omental tissue [19]. According to a 1992 animal study by Adams et al. [20], omental wrap is protective and contributes to wound repair by preventing premature leakage of vulnerable anastomosis and becoming a source of granulation tissue and neovascularization. For

Table 5. Characteristics of outcomes in operative management group $(n=12)$

\begin{tabular}{|c|c|c|c|c|c|c|c|c|c|c|c|c|}
\hline \multirow[t]{2}{*}{ Characteristic } & \multirow{2}{*}{$\begin{array}{c}\text { Bandlysis } \\
(n=1)\end{array}$} & \multicolumn{4}{|c|}{$\begin{array}{l}\text { Adhesiolysis } \\
\qquad(n=4)\end{array}$} & \multicolumn{7}{|c|}{$\begin{array}{l}\text { Segmental resection of small bowel } \\
\qquad(n=7)\end{array}$} \\
\hline & & Case 2 & Case 3 & Case 4 & Case 5 & Case 6 & Case 7 & Case 8 & Case 9 & Case 10 & Case 11 & Case 12 \\
\hline Days from admission to surgery & 5 & 17 & 5 & 13 & 9 & 8 & 6 & 5 & 7 & 6 & 6 & 7 \\
\hline Days from surgery to discharge & 20 & 22 & 13 & 55 & 17 & 31 & 23 & 25 & 9 & 18 & 9 & 16 \\
\hline Operative time (min) & 100 & 110 & 100 & 150 & 155 & 243 & 205 & 110 & 90 & 100 & 95 & 165 \\
\hline Amount of bleeding (mL) & 10 & 10 & 30 & 100 & 10 & 100 & 200 & 50 & 10 & 10 & 5 & 100 \\
\hline Drainage & Yes & No & No & Yes & Yes & No & Yes & No & Yes & Yes & Yes & Yes \\
\hline Morbidity & WC & WC & WC & WC & No & WC & WC & No & No & No & No & No \\
\hline Bowel ischemic change & Yes & No & No & No & No & No & No & Yes & No & No & No & No \\
\hline Bowel stricture & No & No & No & No & No & No & No & No & Yes & Yes & Yes & No \\
\hline
\end{tabular}

WC, wound complication. 
this reason, omentum with abundant adipocytes is called an "abdominal policeman" [21]. Therefore, we hypothesized that at the time of index surgery, the adipocyte-induced anti-inflammatory response of adipocytes in patients with obesity would be effective in reducing risk of intestinal adhesion after surgery. Thus, the results of this study can be explained by the better therapeutic prognosis for SBO after index surgery for patients with obesity.

Initial leukocyte count and CRP level were significantly higher in the operative management group than in the conservative care group. In 2010, Schwenter et al. [22] suggested that clinicoradiological score predicts risk of strangulated SBO. In the study, small bowel resection was significantly more frequently required for leukocyte counts $>10^{4} / \mu \mathrm{L}$ or CRP levels exceeding $7.5 \mathrm{mg} / \mathrm{dL}$. The results of these studies may be due to both leukocyte counts and CRP levels being proportional to inflammation severity.

A limitation of this study is that randomization among the comparative groups was not practical because of the innate characteristics of a retrospective study. Another limitation is the lack of a plan to set a cutoff value for each predictive factor that was found to be significant. In addition, the lack of a study of initial CT findings remains a limitation. Further studies are needed to overcome these limitations and establish more sophisticated SBO management guidelines.

In conclusion, we found that the number of operations before SBO, leukocyte count, CRP level, and BMI were statistically significant factors in patients with SBO treated surgically. By closely examining these factors, we inferred that early selection of patients who need surgery may help improve their therapeutic prognosis.

\section{CONFLICT OF INTEREST}

No potential conflict of interest relevant to this article was reported.

\section{REFERENCES}

1. Richard PG, Pepijn K, Salomone DS, Federico C, Walter LB, Luca $A$, et al. Bologna guidelines for diagnosis and management of adhesive small bowel obstruction (ASBO): 2017 update of the evidence-based guidelines from the world society of emergency surgery ASBO working group. World J Emerg Surg 2018;13:24.

2. Di Saverio S, Catena F, Kelly MD, Tugnoli G, Ansaloni L. Severe adhesive small bowel obstruction. Front Med 2012;6:436-9.

3. Miller G, Boman J, Shrier I, Gordon PH. Etiology of small bowel obstruction. Am J Surg 2000;180:33-6.

4. Bizer LS, Liebling RW, Delany HM, Gliedman ML. Small bowel obstruction: the role of nonoperative treatment in simple intestinal obstruction and predictive criteria for strangulation obstruction. Surgery 1981;89:407-13.

5. Diaz JJ Jr, Bokhari F, Mowery NT, Acosta JA, Block EF, Bromberg WJ, et al. Guidelines for management of small bowel obstruction.
J Trauma 2008;64:1651-64.

6. Teixeira PG, Karamanos E, Talving P, Inaba K, Lam L, Demetriades D. Early operation is associated with a survival benefit for patients with adhesive bowel obstruction. Ann Surg 2013;258:459-65.

7. Hajibandeh S, Hajibandeh S, Panda N, Khan RMA, Bandyopadhyay SK, Dalmia S, et al. Operative versus non-operative management of adhesive small bowel obstruction: a systematic review and meta-analysis. Int J Surg 2017;45:58-66.

8. Catena F, Di Saverio S, Kelly MD, Biffl WL, Ansaloni L, Mandalà $\mathrm{V}$, et al. Bologna Guidelines for Diagnosis and Management of Adhesive Small Bowel Obstruction (ASBO): 2010 EvidenceBased Guidelines of the World Society of Emergency Surgery. World J Emerg Surg 2011;6:5.

9. Meier RP, de Saussure WO, Orci LA, Gutzwiller EM, Morel P, Ris F, et al. Clinical outcome in acute small bowel obstruction after surgical or conservative management. World J Surg 2014;38:3082-8.

10. Lo OS, Law WL, Choi HK, Lee YM, Ho JW, Seto CL. Early outcomes of surgery for small bowel obstruction: analysis of risk factors. Langenbecks Arch Surg 2007;392:173-8.

11. Fevang BT, Jensen D, Svanes K, Viste A. Early operation or conservative management of patients with small bowel obstruction? Eur J Surg 2002;168:475-81.

12. Lou Z, Yan FH, Hu SJ, Meng RG, Zhang W, Yu ED et al. Predictive factors for surgical intervention in patients over the age of 80 with adhesive small-bowel obstruction. Indian J Surg 2015;77: 1280-4.

13. Duron JJ, du Montcel ST, Berger A, Muscari F, Hennet H, Veyrieres $\mathrm{M}$, et al. Prevalence and risk factors of mortality and morbidity after operation for adhesive postoperative small bowel obstruction. Am J Surg 2008;195:726-34.

14. Lee SY, Park KJ, Ryoo SB, Oh HK, Choe EK, Heo SC. Early postoperative small bowel obstruction is an independent risk factor for subsequent adhesive small bowel obstruction in patients undergoing open colectomy. World J Surg 2014;38:3007-14.

15. Angenete E, Jacobsson A, Gellerstedt M, Haglind E. Effect of laparoscopy on the risk of small-bowel obstruction: a populationbased register study. Arch Surg 2012;147:359-65.

16. Miller G, Boman J, Shrier I, Gordon PH. Natural history of patients with adhesive small bowel obstruction. Br J Surg 2000;87: 1240-47.

17. Parker MC, Wilson MS, Menzies D, Sunderland G, Clark DN, Knight AD, et al. The SCAR-3 study: 5-year adhesion-related readmission risk following lower abdominal surgical procedures. Colorectal Dis 2005;7:551-8.

18. Davies DA, Yanchar NL. Appendicitis in the obese child. J Pediatr Surg 2007;42:857-61.

19. Chandra A, Srivastava RK, Kashyap MP, Kumar R, Srivastava RN, Pant AB. The anti-inflammatory and antibacterial basis of human omental defense: selective expression of cytokines and antimicrobial peptides. PLoS One 2011;6:e20446.

20. Adams W, Ctercteko G, Bilous M. Effect of an omental wrap on the healing and vascularity of compromised intestinal anastomo- 


\section{Coloproctology Young Jae cho, et al.}

ses. Dis Colon Rectum 1992;35:731-8.

21. Flint R. Differences in acute general surgical admissions between obese or overweight patients compared to normal-sized patients. N Z Med J 2015;128:35-41.
22. Schwenter F, Poletti PA, Platon A, Perneger T, Morel P, Gervaz P. Clinicoradiological score for predicting the risk of strangulated small bowel obstruction. Br J Surg 2010;1119-25. 